\title{
A TECNOLOGIA COMO ELO ENTRE O DESIGN E A EDUCAÇÃO: o exemplo da "sala de aula invertida"
}

\author{
Geisy Anny Venâncio \\ IFAM - Manaus \\ venancio.anny@gmail.com
}

\begin{abstract}
RESUMO
Este artigo propõe uma reflexão sobre as possibilidades de conexão entre o campo da Educação, em particular da Educação a Distância (EaD), e a área do Design, considerando-se o uso de tecnologias educacionais e os fatores intrínsecos a essa relação. Destaca-se o conceito pedagógico de "sala de aula invertida" como um exemplo de conexão entre os temas Educação, Tecnologia e Design. Para tanto, a pesquisa bibliográfica, neste contexto, é utilizada como procedimento formal principal de coleta de dados, sendo este um estudo de caráter descritivo por apresentar uma compilação sintética de apontamentos a respeito da interdependência entre dois campos do saber: Educação e Design, tendo a tecnologia como principal elo integrador. Essa integração entre os temas é pontuada como uma possível solução para as problemáticas inerentes aos significativos avanços das Tecnologias de Informação e Comunicação (TIC) e, por consequência, a necessidade de incorporação, na cultura escolar, de uma nova forma de ensino-aprendizagem, em um processo que vise a potencialização de competências para que as múltiplas linguagens que convergem, sejam utilizadas. O conceito de tecnologia é aqui utilizado como um meio para aprimorar o processo de comunicação no contexto educacional, em virtude do desafio docente relacionado à correta compreensão da dimensão dialógica e interativa do processo comunicativo, no sentido de construção conjunta de conhecimentos e não mera transmissão de uma informação.
\end{abstract}

Palavras-chave: Educação. Tecnologia. Design. Sala de Aula Invertida.

\section{TECHNOLOGY AS A LINK BETWEEN DESIGN AND EDUCATION: the "flipped classroom" example}

\begin{abstract}
This study proposes a reflection on the possibilities of connection between the field of Education, particularly Distance Education, and the Design area, considering the use of educational technologies and the factors intrinsic to this relationship. For this, we highlight the pedagogical concept of "flipped classroom" as an example of connection between the themes Education, Technology and Design. For this purpose, bibliographic
\end{abstract}


research, in this context, is used as the main formal data collection procedure, with this study having a descriptive character because it presents a synthetic compilation of notes regarding the interdependence between two fields of knowledge: Education and Design, with technology as the main integrating link. The integration between these themes may be a possible solution for the problems inherent to the significant advances of Information and Communication Technologies (ICT) and, consequently, to the need to incorporate in the school culture a new form of teaching-learning, in a process aimes at enhancing skills so that the multiple languages that converge are used. The concept of technology is used here as a means of improving the communication process in the educational context, due to the teacher challenge related to the correct understanding of the dialogic and interactive dimension of the communicative process, in the sense of building knowledge together and not just transmitting information.

Keywords: Education. Technology. Design. Flipped classroom.

\section{LA TECNOLOGÍA COMO UN ENLACE ENTRE DISEÑO Y EDUCACIÓN: el ejemplo "aula invertida"}

\section{RESUMEN}

Este artículo propone una reflexión sobre las posibilidades de conexión entre el campo de la Educación, en particular la Educación a Distancia, y el área de Diseño, considerando el uso de tecnologías educativas y los factores intrínsecos a esta relación. Para ello, el concepto pedagógico de "aula invertida" se destaca como un ejemplo de conexión entre los temas Educación, Tecnología y Diseño. Para ello, la investigación bibliográfica, en este contexto, se utiliza como principal procedimiento formal para la recolección de datos, teniendo este estudio un carácter descriptivo, ya que presenta una recopilación sintética de apuntes sobre la interdependencia entre dos campos del conocimiento: Educación y Diseño, con la tecnología como el principal vínculo de integración. Esta integración entre los temas se puntúa como una posible solución a los problemas inherentes a los avances significativos de las Tecnologías de la Información y la Comunicación (TIC) y, en consecuencia, la necesidad de incorporar, en la cultura escolar, una nueva forma de enseñanza-aprendizaje, en un proceso destinado a mejorar las habilidades para que se utilicen los múltiples idiomas que convergen. El concepto de tecnología se utiliza aquí como un medio para mejorar el proceso comunicativo en el contexto educativo, debido al desafío del docente relacionado con la correcta comprensión de la dimensión dialógica e interactiva del proceso comunicativo, en el sentido de construcción conjunta de conocimientos y no meramente de transmisión de información.

Palabras claves: Educación. Tecnología. Diseño. Aula invertida. 


\section{INTRODUÇÃO}

A evolução das Tecnologias de Informação e Comunicação (TICs) tem proporcionado novas perspectivas para a educação, sobretudo, para a Educação a Distância (EaD). As TICs, de acordo com Maldonado (2007), influenciam a aquisição e transmissão do saber, a natureza dos processos de ensino-aprendizagem, bem como a linguagem, a percepção audiovisual e as capacidades intelectuais dos alunos.

Para o autor, embora as possibilidades das tecnologias sejam bastante significativas, há ainda um abismo entre a maturidade alcançada pelos meios tecnológicos e a falta de maturidade conceitual sobre como e com que objetivo os novos meios de informação e comunicação podem ser corretamente utilizados no contexto da prática educativa.

Nesse cenário, o Design, como área relacionada à cultura visual e que tem a função social de tornar ambientes inteligíveis, segundo Portugal (2013), se apresenta como potencializador do processo de construção do conhecimento, em busca de um equilíbrio entre interesses e necessidades do professor e do aluno, como também de instituições educacionais.

Na Educação a Distância, a exploração das TICs se dá, dentre outras formas, por meio da digitalização de imagens, textos, sons e símbolos, com a finalidade de comunicar e, como consequência, surge a necessidade de reflexão sobre a importância da linguagem digital nos processos educacionais.

Para Amaral e Barros (2007), as constantes modificações no processo comunicativo estabeleceram um tipo de linguagem digital que possui maior interação, pois o receptor também se torna um produtor de mensagens, considerando-se as possibilidades oferecidas pelas TICs.

Assim, no contexto educacional, problematiza-se no sentido de que a aprendizagem, sendo social e mediada por elementos culturais, gera formas de práticas pedagógicas em que a preocupação deve ser expandida para o 'como ensinar' e não somente 'o que ensinar', especialmente levando em consideração que se vive em uma constante instabilidade contemporânea, o que pode ocasionar situações que envolvam maiores desafios pedagógicos, os quais podem ser minimizados, considerando-se, sobretudo, o aspecto comunicacional, por meios tecnológicos.

Nessa perspectiva, considerando-se o cenário de novas possibilidades com o advento da tecnologia, torna-se necessário o aprofundamento de estudos sobre o Design em ambientes educacionais, para que seja possível, a professores e alunos, a organização e a disponibilização de informações, de maneira adequada para o alcance dos objetivos educacionais estabelecidos. 


\section{DESIGN EM PROL DA EDUCAÇÃO}

A área do Design é considerada bastante ampla, apresentando diversas subdivisões, por isso, é possível caracterizar o designer, de um modo geral, como um profissional que necessita ter uma visão sistêmica a respeito do universo que o cerca, no que diz respeito à capacidade de compreender o todo por meio de uma análise das partes complementares e da interação entre elas.

Nesse sentido, Moraes (2009), pautado nas questões das mudanças originadas a partir da formação de uma sociedade pós-industrial e pós-moderna, esclarece que é esperada dos designers uma capacidade de gestão da complexidade que se estabeleceu e se estabelece no cenário atual, a qual é reconhecida pela interrelação entre empresa, mercado, produto, consumo e cultura.

O autor acredita que o foco na atividade de design se ampliou de maneira a aproximá-lo de contornos e de fronteiras anteriormente tidas como longínquas e que a realidade do século XXI exige dos designers uma nova postura a respeito da concepção de artefatos e dos produtos-serviço.

Ainda nesse viés, Berman (2009) pontua que os designers têm uma responsabilidade social essencial porque o Design está no cerne dos maiores desafios (e soluções) do mundo. Para ele, os designers criam muito do mundo em que se vive, das coisas que são consumidas e das expectativas geradas. Designers moldam o que é visto, usado e desperdiçado e, com isso, têm uma enorme influência no modo como o homem se envolve com o mundo a sua volta e como encara seu futuro.

Assim sendo, uma vez que, como apontado por Bonsiepe (2011), o campo do Design perdeu a sua substância quando passou a tratar das superficialidades, há que se pensar a desmaterialização do Design para que esta área esteja mais consciente e ativa na sua função social de tornar ambientes mais inteligíveis, oferecendo, dessa forma, soluções efetivas no que se refere a ambientes educacionais hipermídia.

Reconhece-se que, por vezes, ainda há uma certa banalização do termo "design", o qual costuma ser comumente associado à artigos de luxo. No entanto, o termo está essencialmente atrelado à 'desígnio', enquanto intenção, propósito, o que faz com que os profissionais dessa área assumam um importante papel "[...] no que tange a desenhar/projetar novas formas de vida - de lazer, trabalho, ensino e moradia -, novas relações humanas e interações com os artefatos - materiais ou digitais", que podem estar relacionadas a contextos de incertezas (como uma Pandemia), ou fora dele (VASQUES, 2020, online, grifo nosso).

Torna-se necessária, então, uma especial atenção quanto às novas demandas da sociedade contemporânea e as possibilidades de conexão do Design com outros campos do saber, como a Educação, objeto deste estudo.

Considerando-se a conexão do Design com a Educação, emerge o conceito 
de Design Instrucional (DI) ou Design Educacional que, segundo Filatro (2008, p. 3) apresenta-se "como o processo (conjunto de atividades) de identificar um problema (uma necessidade) de aprendizagem e desenhar, implementar e avaliar uma solução para esse problema".

O design, enquanto elemento de comunicação, volta sua visão aos aspectos não palpáveis das aplicações pedagógicas dos objetos relativas ao campo visual. É elevado seu potencial de utilização como canal de diálogo entre os educadores e seus alunos nas mais diferentes disciplinas. Essas práticas podem dinamizar o processo de ensino-aprendizagem na medida em que criam combinações harmônicas entre universos distintos com finalidades comuns: o aprimoramento individual e coletivo. (COUTINHO; LOPES, 2011, p. 159).

Uma vez que o mundo vem passando por um importante período de transição, estando evidenciado esse necessário aprimoramento individual e coletivo, os desafios emergentes envolvem diferentes aspectos culturais, sociais, ambientais, econômicos, políticos e educacionais, e a compreensão do mundo deve considerar um contexto mais holístico, global e sistêmico, reconhecendo-se que a instabilidade contemporânea envolve "a necessidade da interatividade, da interdependência e da interconectividade entre os homens [...] [com um] novo pensar e agir [e] gera necessidades às quais as escolas, professores e alunos precisam se adaptar." (PORTUGAL; COUTO, 2010, p. 6).

Acredita-se, assim, que um diálogo interdisciplinar entre Educação e Design, com base nos efeitos que as novas tecnologias estão provocando na imagem, na linguagem e na cultura, pode oferecer um novo olhar e uma nova maneira de lidar com as problemáticas relacionadas aos significativos avanços das tecnologias de informação e comunicação e, por consequência, a necessidade de incorporação, na cultura escolar, de uma nova forma de ensino-aprendizagem.

\section{O CONCEITO DE "SALA DE AULA INVERTIDA"}

O conceito de Sala de Aula Invertida (tradução do termo em inglês Flipped Classroom) merece atenção, uma vez que se trata de uma metodologia de ensino que inverte o processo de aprendizagem tradicional do aluno: a aquisição do conhecimento não acontece apenas em aulas expositivas presenciais, mas também à distância, com o auxílio de recursos tecnológicos, permitindo que o aluno assuma o papel de sujeito de sua própria aprendizagem e posicionando o professor como mediador desse processo.

Sala de aula invertida é o nome que se dá ao método que inverte a lógica de organização da sala de aula. Conceito idealizado por Jonathan Bergmann, em 
parceria com Aaron Sams ${ }^{1}$, essa abordagem se torna viável em virtude da crescente popularização do vídeo digital distribuído online por meio de serviços como youtube ou de recursos de áudio como o podcast. "A ideia é que o aluno leia, faça atividades e aprenda em casa. Na sala de aula, cabe ao Professor tirar as dúvidas e aprofundar os conteúdos, promovendo debates e servindo de mediador". (BARRETO, 2013).

A proposta é que os alunos possam assistir, em casa, explicações curtas, diretas e objetivas em vídeos, por meio de uma gama cada vez mais diversificada de dispositivos como smartphones, tablets, notebooks, etc. Já na sala de aula, o tempo é utilizado para ser aplicado em atividades de aprendizagem diversas, com o professor disponível para orientar, apoiar e tirar dúvidas dos estudantes, os quais possuem diferentes formas de lidar com a ato de aprender.

Sabe-se que há diferentes estilos de aprendizagem, cabendo aqui reforçar que tais estilos apenas sugerem tendências, pois essa questão envolve uma série de outras variáveis que não só o simples 'se identificar mais' com uma ou outra estratégia didática, uma vez que não se trata de algo estático. Enquanto 'estilos'/preferências associados a pessoas, entende-se que a variação é inevitável e dependente de experiências individuais, com contextos diversos e, por isso, o papel do estudante é variável, exigindo que o design instrucional também o seja, uma vez que este se diferencia de acordo com o modelo seguido, o qual é adotado com base em determinada realidade educacional, considerando contextos e padrões de utilização de tecnologias variáveis

O design instrucional, segundo Filatro (2008), é o processo de identificação de um problema de aprendizagem e a busca por uma solução. A autora Filatro (2008, p. 3), aponta o:

Design instrucional como a ação intencional e sistemática de ensino que envolve o planejamento, o desenvolvimento e a aplicação de métodos, técnicas, atividades, materiais, eventos e produtos educacionais em situações didáticas específicas, a fim de promover, a partir dos princípios de aprendizagem e instrução conhecidos, a aprendizagem humana.

Dessa forma, tomando-se como base a classificação de Filatro (2008, p. 20) acerca dos modelos de design instrucional (DI), o conceito de "Sala de Aula Invertida" poderia ser melhor caracterizado como direcionado a um modelo de DI Contextualizado, o qual estabelece a atividade humana como central, no entanto, sem a exclusão da "possibilidade de utilização de unidades [de estudo] fixas e préprogramadas, conforme objetivos, domínio de conhecimento e contextos específicos".

\footnotetext{
${ }^{1}$ A ideia do projeto Sala de Aula Invertida ou Flipped Classroom veio de dois professores americanos, Jonathan Bergman e Aaron Sams, que lecionavam em escolas de ensino médio nos Estados Unidos. Muitos dos seus alunos eram atletas e precisavam se ausentar das aulas regulares por longos períodos de tempo. A partir daí os professores criaram essa estratégia diferenciada, para que esses estudantes pudessem praticar os esportes sem prejudicar os estudos. (ICnews, 17 mar 2014).
} 
Assim, na proposta pedagógica do conceito de Sala de Aula Invertida, as atividades realizadas e o tipo de material utilizado pelo estudante, quando ele está fora da sala de aula ou em sala de aula, devem variar de acordo com os objetivos de aprendizagem envolvidos, criando diferentes possibilidades para essa abordagem.

Valente (2014, p. 86) aponta que as "regras básicas para inverter a sala de aula", com base no Guia de campo da Sala de Aula Invertida - 2014 são:

1) as atividades em sala de aula envolvem uma quantidade significativa de questionamento, resolução de problemas e de outras atividades de aprendizagem ativa, obrigando o aluno a recuperar, aplicar e ampliar o material aprendido on-line; 2) Os alunos recebem feedback imediatamente após a realização das atividades presenciais; 3 ) Os alunos são incentivados a participar das atividades on-line e das presenciais, sendo que elas são computadas na avaliação formal do aluno, ou seja, valem nota; 4) tanto o material a ser utilizado on-line quanto os ambientes de aprendizagem em sala de aula são altamente estruturados e bem planejados. (VALENTE, 2014, p. 86).

Em suma, esse conceito de sala de aula busca enfatizar a utilização de tecnologias para que o aprendizado seja aprimorado, permitindo ao professor otimizar o seu tempo em sala de aula com atividades mais interativas, em vez de gastar o tempo ministrando, prioritariamente, aulas expositivas tradicionais.

De acordo com Zwicker (2017, p. 65), a sala de aula invertida é uma "metodologia ativa, investigativa e colaborativa", na qual o estudante é o "protagonista no processo de aprendizagem", sendo orientado/instigado a investigar sobre determinado assunto antes da aula e chegar preparado para uma discussão, o que acabe por possibilitar que a aula seja mais dialógica e interativa.

Esse conceito de sala de aula invertida pode também ser considerado associando-se a lógica de atividades presenciais com a lógica da sincronicidade, ampliando a proposta de inversão da sala de aula, sem que necessariamente esteja vinculada à presença física em um mesmo espaço/ambiente, mas à interação síncrona (em tempo real). Essa adaptação pode ser útil em situações de incerteza, em que os encontros presenciais não podem ser realizados e, assim sendo, é possível adaptar a proposta de inverter a sala de aula, valendo-se da associação dos momentos presenciais com os momentos síncronos e das atividades fora da sala com os momentos assíncronos, ambos auxiliados por recursos tecnológicos.

Como exemplo concreto de aplicação desse conceito em um contexto de incerteza, tendo-se como pano de fundo a Pandemia causada pela Covid-19, um estudo realizado por Nascimento e Rosa (2020) evidenciou que os princípios da Sala de Aula Invertida podem ser aplicados para dar continuidade na rotina de aprendizagem, apontando-se a necessidade de repensar a prática pedagógica no sentido de buscar metodologias inovadoras em sala de aula. 


\section{A UTILIZAÇÃO DAS TICS NO CONTEXTO EDUCACIONAL}

Diversos estudos e pesquisas sobre a Educação têm analisado a influência das TICs no processo de ensino-aprendizagem.

Brito e Purificação (2008, p. 26) defendem que, diante do advento das TICs, faz-se necessário que as organizações educacionais estejam abertas a um projeto de reflexão e ação, com incentivo contínuo às mais diversas experiências, pois a diversidade de situações pedagógicas exige a reelaboração e a reconstrução do processo de ensino-aprendizagem.

Assim, Cazarini et al (2012) defendem que as significativas e profundas mudanças tecnológicas aliadas à velocidade de informação na sociedade contemporânea, têm gerado alterações no relacionamento entre as pessoas e, como consequência, no 'ser educador' e 'fazer educação'.

Nessa direção, segundo Musacchio (2013), as tecnologias e as pressões sociais direcionam para um estilo novo de vida e uma nova maneira de encarar a construção do conhecimento, em um contexto de consumo informacional e processos colaborativos.

Conforme aponta Mill (2013), vários pesquisadores têm investigado a carreira docente, no entanto ainda há lacunas a serem preenchidas a respeito da formação do professor, sobretudo considerando-se a relação da docência com as TICs, uma vez que a formação do educador se torna mais desafiadora ao agregar novos elementos e condições de trabalho diferenciadas.

\footnotetext{
Diversos pesquisadores e teóricos têm se debruçado, durante os últimos anos, para entender a constituição da atividade docente: o que é docência, como funciona, como se aprende a ser professor, quais as principais dificuldades do ato de ensinar, as mudanças ocorridas no trabalho do docente, sua formação, seus saberes, entre outros. Apesar de todo o esforço dos pesquisadores/pensadores da área, podemos considerar que o entendimento da docência ainda é parcial, fragmentado e insuficiente para romper com certas limitações da profissionalização do educador. Quando pensamos as interseções entre educação e tecnologias digitais, a docência apresenta-se como campo fértil para pesquisas e carente de desbravamentos investigativos. (MILL, 2013, p. 347).
}

O autor acima citado aponta ainda que a promoção de outras formas educacionais foi possível em virtude de sistemas e dispositivos gerados pelas TICs, os quais fazem com que o docente tenha seu papel redimensionado por meio das novas configurações existentes para a educação, como a utilização de dispositivos móveis, ambientes virtuais de ensino-aprendizagem e redes sociais. Para Mill (2013, p. 349), "as tecnologias digitais induzem novas reflexões sobre as formas de ensinar e, também, sobre a aprendizagem da docência". 
Em sua pesquisa, Mill $(2013$, p. 349$)$ estabelece uma fundamentação teórica temporal evolutiva, com base na afirmação de autores como Sancho (1997), Lévy (1999), Litwin (2001), Belloni (2003), Castells (2003) e Kenski (2008), para enfatizar que determinados aspectos decorrentes da emergência das TICs "já não podem ser ignorados nas reflexões sobre o ensino-aprendizagem e muito menos nas práticas pedagógicas contemporâneas", justificando assim a "necessidade de pesquisas e proposições de novas formas de agregar valor ao ensino-aprendizagem pela incorporação de possibilidades tecnológicas emergentes".

Faz-se necessário enfatizar que o uso da tecnologia no contexto educacional sem uma real consciência por parte dos envolvidos não significa, por si só, uma melhoria no processo de ensino e aprendizagem. Há que se atentar para a necessidade de um bom planejamento conceitual e metodológico, para não se incorrer no erro de "replicar um mesmo paradigma educacional, sob a falsa expectativa de inovação, mediante uma diferente plataforma" (VIEIRA JUNIOR, 2018, p. 35).

Além disso, é importante considerar uma ampla gama de fatores que podem dificultar a implantação, na cultura escolar, do uso de TICs, uma vez que são diversos os contextos e os impasses socioeconômicos e culturais são reais. Sob o aspecto cultural, compreende-se que a tecnologia representa uma "nova metodologia" de ensino implantada em um sistema secular, o que pode envolver resistência à mudanças ou, como no caso de situações de incertezas e/ou mudanças obrigatórias e urgentes, a dificuldade no uso de recursos tecnológicos justamente por não se considerar tal prática no contexto escolar como algo recorrente e essencial.

\footnotetext{
Pesquisas apontam que, quando o assunto é ensino a distância, o trabalho dos professores tem papel significativo no sentido de assegurar uma boa experiência, independentemente da solução utilizada. [...] No caso do uso de tecnologias educacionais [...], as evidências são claras em apontar que os docentes possuem papel fundamental para que essas soluções tenham resultado positivo no desempenho acadêmico dos estudantes [...] é relevante entender o nível de formação dos docentes para trabalhar com recursos tecnológicos. (TODOS PELA EDUCAÇÃO, 2020, p. 13).
}

Nessa perspectiva, considerando-se o cenário de novas possibilidades para a prática docente em virtude do advento da tecnologia, torna-se necessário o aprofundamento de estudos sobre a formação do professor e a apropriação crítica da tecnologia, a serviço de uma educação de qualidade, para que seja possível, a professores e alunos, a organização e disponibilização de informações, para a efetiva construção do conhecimento. 


\section{CONSIDERAÇÕES FINAIS}

Acredita-se que um diálogo interdisciplinar entre Tecnologia, Educação e Design, com base nos efeitos que as novas tecnologias estão provocando na imagem, na linguagem e na cultura, pode oferecer um novo olhar e uma nova maneira de lidar com as problemáticas relacionadas aos significativos avanços das tecnologias de informação e comunicação. Assim, há que se atentar para a necessidade de adaptação do processo de ensino-aprendizagem às novas demandas da sociedade contemporânea.

Nesse sentido, confirma-se a necessidade de atentar para a utilização das tecnologias diversas no contexto educacional, sobretudo na modalidade a distância, pois a Educação a Distância (EaD) tem particularidades que devem ser levadas em consideração, embora a essência do processo de ensino-aprendizagem seja a mesma da modalidade presencial: a busca pela construção do conhecimento.

No entanto, é possível apontar que, na EaD, a ação docente difere em relação ao ensino presencial, principalmente no que diz respeito à polidocência ${ }^{2}$ e a busca constante para suprir eventuais lacunas decorrentes do distanciamento físico entre docente e discentes.

Conceitos pedagógicos inovadores como o da "sala de aula invertida" devem ser amplamente estudados no sentido de se atestar ou não a sua viabilidade nos mais diversos contextos da educação, com o olhar sempre atento aos diferentes estilos de aprendizagem.

Faz-se necessário levar em consideração e observar os diferentes estilos de aprendizagem dos estudantes para que o docente, compreendendo a diversidade existente entre os alunos, possa vislumbrar a adoção de novas metodologias mais apropriadas para atingir o máximo possível de alunos na efetiva construção do conhecimento e não apenas na superficial transmissão da informação.

O docente está sendo desafiado a adequar o 'fazer educação' (por meio da sua prática pedagógica) às imposições geradas pelas transformações tecnológicas. Assim, acredita-se que as tecnologias podem auxiliar a prática docente somente se forem utilizadas como potencializadoras no processo de construção do conhecimento pelo aluno, e não somente como ferramentas inseridas aleatoriamente no contexto educacional, com uma prática docente descontextualizada, possibilitando apenas a transmissão da informação.

As funções dos docentes devem ser repensadas em virtude das mudanças que ocorrem constantemente na sociedade e que influenciam nos recursos educacionais disponíveis, o que acaba por exigir que o docente considere

\footnotetext{
${ }^{2} \mathrm{Na}$ Educação a Distância (EaD) o trabalho docente é organizado coletivamente, em um ambiente de cooperação o que, para Mill (2010, p. 23), é definido como polidocência, ou seja, um "conjunto articulado de trabalhadores, necessário para a realização das atividades de ensino-aprendizagem na EaD".
} 
a possibilidade/necessidade de se portar muito mais como um intermediário de uma gama de informações disponíveis do que de detentor do conhecimento.

Nesse viés, e considerando esse contexto contemporâneo tão 〈líquido〉, cheio de mudanças imprevisíveis, a educação requer mais abertura, diálogo, flexibilidade e ubiquidade e deve ser "pensada durante a vida inteira", como defendido por Zygmunt Bauman.

Há também que se considerar constantemente toda a pluralidade existente em um país tão diversos quanto o Brasil (e a significativa desigualdade social) sem que se ignore que a educação não deve se restringir à transmissão de informação a qualquer custo.

O real propósito da educação está vinculado a uma construção do conhecimento em que, independente da modalidade (presencial, à distância, ensino remoto ou outra), o mero uso de TICs não atesta um avanço, uma vez que não se trata mais de incluir digitalmente os atores envolvidos, mas de otimizar todo o processo comunicativo envolvido no contexto educacional.

Para tanto, defende-se que a conexão entre os temas Tecnologia, Educação e Design e a comprovação de que uma consciente e efetiva conectividade entre as áreas da Educação e do Design, tendo a tecnologia como elo principal, pode influenciar, de maneira positiva, na inclusão de pessoas com diferentes estilos para aprender, na relação de ensino-aprendizagem, abrindo assim, novos caminhos para a melhoria do processo educativo.

\section{REFERÊNCIAS}

AMARAL, Sergio F.; BARROS, Daniela M. V. Estilos de aprendizagem no contexto educativo de uso das tecnologias digitais interativas. Disponível em: http://lantec. fae.unicamp.br/lantec/portugues/tvdi_portugues.pdf. Acesso em: 14 set. 2013.

BARRETO, Andrea. Sala de Aula Invertida. In: Dicas de Ciências. Disponível em: https://dicasdeciencias.com/2013/08/03/sala-de-aula-invertida/. Acesso em: 9 jun. 2014

BELLONI, Maria Luiza. Educação a Distância. 3. ed. Campinas, SP: Autores Associados, 2003.

BERMAN, David. B. Do good design - How designers can change the world. California: Aiga - New Riders, 2009.

BONSIEPE, Gui. Design, cultura e sociedade. São Paulo: Edgar Blucher, 2011.

BRITO, Glaucia da Silva; PURIFICAÇÃO, Ivonélia da. Educação e novas tecnologias: um re-pensar. 2. ed. rev., atual. e ampl. Curitiba: Ibpex, 2008.

CASTELLS, Manuel. A galáxia da Internet: reflexões sobre a Internet, os negócios e a sociedade. Rio de Janeiro: Jorge Zahar, 2003. 
CAZARINI, Edson W.; NETO, José Dutra O.; OLIVEIRA, Selma Regina M.; TIZIOTTO, Simone Aparecida. Reflexões sobre a inovação na Educação a Distância: o caso brasileiro. EAD em foco - Revista Científica em Educação a Distância. n. 2, p. 94 - 118. Fundação CECIERJ, novembro, 2012. Disponível em: http://eademfoco.cecierj.edu.br/index.php/ Revista/article/view/91/30.Acesso em:14 set. 2013.

COUTINHO, Solange Galvão; LOPES, Maria Teresa. Design para educação: uma possível contribuição para o ensino fundamental brasileiro. In: BRAGA, Marcos da Costa (org.). O Papel social do design gráfico: história, conceitos \& atuação profissional. São Paulo: Editora SENAC, p. 137-162, 2011.

FILATRO, Andrea. Design instrucional na prática. São Paulo: Pearson Education do Brasil, 2008.

KENSKI, Vania Moreira. Educação e tecnologias: o novo ritmo da informação. Campinas: Papirus, 2008.

LÉVY, Pierre. Cibercultura. Trad. Carlos Irineu da Costa. São Paulo: Editora 34, 1999.

LITWIN, Edith. (org.). Tecnologia educacional: política, histórias e propostas. Porto Alegre: Artmed, 2001.

MALDONADO, Tómas. Memoria y conocimiento: sobre los destinos del saber en la perspectiva digital. Barcelona, Gedisa, 2007.

MILL, Daniel. Análise da educação a distância como interseção entre a formação docente, as tecnologias digitais e a pós-graduação. Educação em Perspectiva, Viçosa, v. 4, n. 2, p. 343-369, jul./dez. 2013. Disponível em: http://www.seer.ufv.br/seer/educacaoemperspectiva/ index.php/ppgeufv/article/viewFile/413/116. Acesso em: 8 jan. 2016.

MORAES, Dijon. O Papel atual do design. In: KRUCKEN, Lia. Design e Território: valorização de indentidades e produtos locais. São Paulo: Studio Nobel, 2009.

MUSACCHIO, Claudio. Redes sociais: uma nova educação é possível? In: Baguete. 02 jan. 2013. Portal EAD Brasil Entrevista. Disponível em: http://www.baguete.com.br/colunas/ claudio-de-musacchio/02/10/2013/redes-sociais-uma-nova-educacao-e-possivel. Acesso em: 8 jan. 2016.

NASCIMENTO, Francisca Georgiana M. do; ROSA, José Victor Acioli da. Princípio da sala de aula invertida: uma ferramenta para o ensino de química em tempos de pandemia. Brazilian Journal of Development, v. 6, n. 6, p. 38513-38525, 2020. Disponível em: https://www.brazilianjournals.com/index.php/BRJD/article/ view/11816/9880. Acesso em: 06 set. 2020.

PORTUGAL, Cristina. Design, educação e tecnologia. Rio de Janeiro: Rio Books, 2013.

PORTUGAL, Cristina; COUTO, Rita. Design em situações de ensino-aprendizagem. Estudos em Design, v. 18, n. 1, 2010. Disponível em: https://estudosemdesign.emnuvens.com.br/ design/article/view/42/39. Acesso em: 06 set. 2020.

SANCHO, Juana M. (org.). Para uma tecnologia educacional. Porto Alegre: Artmed, 1997. 
TODOS PELA EDUCAÇÃO. Ensino a Distância na Educação Básica frente à Pandemia da COVID-19: análise e visão do Todos Pela Educação sobre a adoção de estratégias de ensino remoto frente a cenário de suspensão provisória das aulas presenciais. São Paulo: TPE, 2020. Disponível em: https://www.todospelaeducacao.org.br/_uploads/_posts/425.pdf. Acesso em: 06 set. 2020.

VALENTE, José Armando. Blended learning e as mudanças no ensino superior: a proposta da sala de aula invertida. Educ. rev., Curitiba,n. 4,p.79-97, 2014. Disponívelem: http://www.scielo.br/scielo.php?script=sci_arttext\&pid=S0104-40602014000800079 \&lng=en\&nrm=iso. Acesso em: 25 maio $20 \overline{16}$.

VASQUES, Rosana. O Design como aliado em tempos de Pandemia: disciplinas da Pós-Graduação em Design de Interação exploram soluções na área com a criação de produtos digitais. Entrevista cedida a Patricia Mariuzzo. [S.L.]: PUC-Campinas, 12 jun. 2020. Disponível em https://www.puc-campinas.edu.br/o-design-como-aliado-emtempos-de-pandemia/. Acesso em: 06 set. 2020.

VIEIRA JUNIOR, Niltom. Tecnologias e Comunicação na Educação. Apostila (Pósgraduação em Docência). Instituto Federal de Minas Gerais. Arcos: IFMG, 2018.

\section{BIOGRAFIA DA AUTORA}

GEISY ANNY VENÂNCIO - Mestre em Design pelo Programa de Pós-Graduação em Design da Universidade Federal do Paraná (UFPR). Especialista em Planejamento, Implementação e Gestão da EaD, pela Universidade Federal Fluminense (UFF). Especialista em Educação a Distância, com habilitação em Tecnologias Educacionais, pelo Instituto Federal de Educação, Ciência e Tecnologia do Paraná (IFPR). Especialista em Design Instrucional para EaD Virtual pela Universidade Federal de Itajubá (UNIFEI). Bacharel em Desenho Industrial com habilitação em Projeto do Produto, pela Universidade Federal do Amazonas (UFAM). Professora efetiva do Instituto Federal de Educação, Ciência e Tecnologia do Amazonas (IFAM), Campus Manaus - Distrito Industrial, desde 2014.

Data de recebimento: 01/09/2020

Data de aprovação: 23/10/2020 